\title{
Long-term outcomes after percutaneous coronary intervention for chronic total occlusion (from the CREDO-Kyoto registry cohort-2).
}

\section{$\operatorname{AUTHOR}(S):$}

Yamamoto, Erika; Natsuaki, Masahiro; Morimoto, Takeshi; Furukawa, Yutaka; Nakagawa, Yoshihisa; Ono, Koh; Mitsudo, Kazuaki; ... Tamura, Takashi; Tanaka, Masaru; Kimura, Takeshi

\section{CITATION:}

Yamamoto, Erika ...[et al]. Long-term outcomes after percutaneous coronary intervention for chronic total occlusion (from the CREDO-Kyoto registry cohort-2).. The American journal of cardiology 2013, 112(6): 767-774

\section{ISSUE DATE:}

\section{3-09-15}

\section{URL:}

http://hdl.handle.net/2433/179527

\section{RIGHT:}

(C) 2013 Elsevier Inc:; This is not the published version. Please cite only the published version.; この論文は出版社版でありません。引用の際に は出版社版をご確認ご利用ください。 


\section{Long-Term Outcomes after Percutaneous Coronary Intervention for Chronic Total Occlusion (From the CREDO-Kyoto registry Cohort-2)}

Erika Yamamoto, $\mathrm{MD}^{\mathrm{a}}$, Masahiro Natsuaki, MD ${ }^{\mathrm{a}}$, Takeshi Morimoto, $\mathrm{MD}^{\mathrm{b}}$, Yutaka Furukawa, $\mathrm{MD}^{\mathrm{c}}$, Yoshihisa Nakagawa, MD ${ }^{\mathrm{d}}$, Koh Ono, $\mathrm{MD}^{\mathrm{a}}$, Kazuaki Mitsudo, MD ${ }^{\mathrm{e}}$, Masakiyo Nobuyoshi, MD ${ }^{\mathrm{f}}$, Osamu Doi, $\mathrm{MD}^{\mathrm{g}}$, Takashi Tamura, $\mathrm{MD}^{\mathrm{h}}$, Masaru Tanaka, $\mathrm{MD}^{\mathrm{i}}$, Takeshi Kimura, $\mathrm{MD}^{\mathrm{a}}$, on behalf of the CREDO-Kyoto PCI/CABG registry cohort-2 investigators.

${ }^{\text {a }}$ Department of Cardiovascular Medicine, Kyoto University Graduate School of Medicine, Kyoto, Japan; ${ }^{\mathrm{b}}$ Center for General Internal Medicine and Emergency Care, Kinki University School of Medicine, Osaka-Sayama, Japan; 'Department of Cardiovascular Medicine, Kobe City Medical Center General Hospital, Kobe, Japan; ${ }^{\mathrm{d} D i v i s i o n}$ of Cardiology, Tenri Hospital, Tenri, Japan; 'Division of Cardiology, Kurashiki Central Hospital, Kurashiki, Japan; ${ }^{\mathrm{f}}$ Division of Cardiology, Kokura Memorial Hospital, Kitakyushu, Japan; ${ }^{\mathrm{g}}$ Division of Cardiology, Shizuoka General Hospital, Shizuoka, Japan; ' Division of Cardiology, Japanese Red Cross Wakayama Medical Center, Wakayama, Japan; 'Division of Cardiology, Osaka Red Cross Hospital, Osaka, Japan

Short title: Outcomes after PCI for CTO

Corresponding Author:

Masahiro Natsuaki, MD,

Department of Cardiovascular Medicine, Graduate School of Medicine, Kyoto University

54 Shogoin Kawahara-cho, Sakyo-ku, Kyoto

606-8507 Japan

Tel: +81-75-751-4254 FAX: +81-75-751-3289

E-mail: natsuaki@kuhp.kyoto-u.ac.jp 


\begin{abstract}
Despite improving success rate of percutaneous coronary intervention (PCI) for chronic total occlusion (CTO)
\end{abstract} lesions, the clinical benefit of recanalization of CTO is still a matter of debates. The purpose of this study is to elucidate the impact of successful PCI for CTO on cardiovascular outcome in a large Japanese observational database of patients who underwent first coronary revascularization. Among 13087 patients who underwent PCI in the CREDO-Kyoto registry Cohort-2, 1524 patients received PCI for CTO. Clinical outcomes were compared between 1192 patients with successful CTO-PCI and 332 patients with failed CTO-PCI. In-hospital death tended to occur less frequently in the successful CTO-PCI group than in the failed CTO-PCI group (1.4\% vs. $3.0 \%$, $\mathrm{P}=0.053)$. Through 3-year follow-up, the cumulative incidence of all-cause death was not significantly different between the successful and failed CTO-PCI groups $(9.0 \%$ vs. $13.1 \%, \mathrm{p}=0.18)$, while the cumulative incidence of cardiac death was significantly lower in the successful CTO-PCI group than in the failed CTO-PCI group (4.5\% vs. 8.4\%, $\mathrm{P}=0.03)$. However, after adjusting confounders, successful PCI for CTO was not associated with lower risk for all-cause death (Hazard ratio [HR]: 0.93, 95\% confidence interval [CI]: 0.64-1.37, $\mathrm{P}=0.69$ ) nor for cardiac death (HR: $0.71,95 \% \mathrm{CI}: 0.44-1.16, \mathrm{P}=0.16$ ). The cumulative incidence of coronary artery bypass grafting (CABG) was remarkably lower in patients with successful PCI compared to those with failed PCI (1.8\% vs. $19.6 \%, \mathrm{P}<0.0001)$. In conclusion, successful PCI for CTO as compared with failed PCI was not associated with lower risk for 3-year mortality.

Key words: chronic total occlusion, percutaneous coronary intervention, coronary artery disease, prognosis. 


\section{Text}

Percutaneous coronary intervention (PCI) for chronic total occlusion (CTO) has dramatically changed in recent years. The improvement of devices such as the guidewires, microcatheters, as well as low-profile balloon catheters and refinement of operator techniques such as parallel wire technique and retrograde approach have contributed to the improved success rate for CTO-PCI, although the penetration rates of parallel wire technique and retrograde approach might be different between Japan and outside Japan. ${ }^{1}$ Furthermore, introduction of drug-eluting stent (DES) has significantly reduced the restenosis and reocclusion rates in the CTO lesions. ${ }^{2-3}$ Successful CTO-PCI has been reported to be associated with less subsequent coronary artery bypass grafting (CABG), improvement of left ventricular function and relief of symptoms. ${ }^{4-6}$ There are several reports that successful CTO-PCI improved the long-term survival outcomes after revascularization. ${ }^{7-8}$ Recently, Mehran and Jones also reported successful PCI for CTO was independently associated with lower cardiac morality. ${ }^{9-10}$ However, many previous studies were associated with relatively low procedural success rates. Procedural success rate itself might have significant influence in analyzing the effect of successful CTO-PCI on survival outcome. Survival outcome after CTO-PCI should also be investigated in a population with relatively high procedural success rates. Therefore, we analyzed the impact of successful PCI for CTO on cardiovascular outcomes in a large Japanese observational database of patients who underwent first coronary revascularization.

\section{Methods}

The CREDO-Kyoto (Coronary REvascularization Demonstrating Outcome study in Kyoto) percutaneous coronary intervention $(\mathrm{PCI})$ /coronary artery bypass grafting $(\mathrm{CABG})$ registry cohort-2 is a multi-center registry 
enrolling consecutive patients undergoing first coronary revascularization procedures among 26 centers in Japan between January 2005 and December 2007 (Supplementary Appendix A). The relevant review boards or ethics committees in all participating centers approved the research protocol. Because of retrospective enrollment, written informed consents from the patients were waived; however, we excluded those patients who refused participation in the study when contacted for follow-up. This strategy is concordant with the guidelines for epidemiological studies issued by the Ministry of Health, Labor and Welfare of Japan.

The design and patient enrollment of the CREDO-Kyoto PCI/CABG registry cohort-2 has been described previously. ${ }^{11}$ Among a total of 15263 patients, 13087 patients underwent PCI as their first coronary revascularization procedure during the 3 years of enrollment period. Among 2491 patients (19\%) with at least 1 CTO lesion, 1524 patients underwent attempt of PCI for CTO lesions. PCI for at least one CTO lesion was successful in 1192 patients (successful CTO-PCI group), while PCI for CTO lesions was unsuccessful in 332 patients (failed CTO-PCI group) (78\% initial patient success rate for CTO) (Figure 1). The number of cases and initial success rate of CTO-PCI in each participating center were illustrated in Supplemental Figure 1. In the successful PCI group, 1230 lesions out of 1245 CTO lesions in 1192 patients were successfully treated (1154 patients had 1 treated CTO lesion and 38 patients had 2 treated CTO lesions). A total of 2032 stents were used in the successful CTO-PCI group; 1589 were drug-eluting stents (78\%) and 443 were bare-metal stents (22\%). In the failed PCI group, no CTO lesion among 339 CTO lesions in 332 patients was successfully treated, while 262 non-CTO lesions were successfully treated in 177 patients. In the current pre-specified substudy of the 
CREDO-Kyoto PCI/CABG registry cohort-2, we compared 3-year clinical outcome between the successful and failed CTO-PCI groups.

Definitions of baseline clinical characteristics were described previously. ${ }^{11}$ CTO was defined as complete obstruction of the vessel with Thrombolysis In Myocardial Infarction (TIMI) flow of 0 or 1 with an estimated duration of the occlusion $>1$ month or presence of collateral flow. The duration of occlusion was judged by the investigators in each participating center on the basis of the interval from the last episode of myocardial infarction (MI) in the target vessel territory, the previous coronary angiography, or changes in electrocardiographic findings. Procedural success was defined as a final diameter stenosis of $<50 \%$ and a TIMI flow of 2 or 3.

All-cause death was regarded as the primary outcome measure in the current analysis. Cardiac death, MI, stroke, stent thrombosis (ST), CABG and any coronary revascularization were also assessed as endpoints. Death was regarded as cardiac in origin unless an obvious non-cardiac cause could be identified. Any death during the index hospitalization was regarded as cardiac death. $M I$ was defined according to the definition in the Arterial Revascularization Therapy Study. ${ }^{12}$ Within 1 week of the index procedure, only Q-wave MI was adjudicated as MI. Stroke was defined as ischemic or hemorrhagic stroke either occurring during the index hospitalization or requiring hospitalization with symptoms lasting $>24$ hours. $S T$ was defined according to the Academic Research Consortium (ARC) definition. ${ }^{13}$ ARC definite ST was used as the end point for ST in this study. The recommend antiplatelet regimen was aspirin ( $\geq 81 \mathrm{mg}$ daily) indefinitely and thienopyridine (200 $\mathrm{mg}$ ticlopidine or $75 \mathrm{mg}$ clopidogrel daily) for at least 3 months. Duration of antiplatelet therapy was left to the discretion of each attending physician. 
Demographic, angiographic, and procedural data were collected from hospital charts or databases

according to the pre-specified definitions by the experienced clinical research coordinators in the independent clinical research organization (Research Institute for Production Development, Kyoto, Japan) (Supplementary Appendix B). Follow-up data were collected also by the experienced clinical research coordinators from hospital charts or by contacting patients, or referring physicians. Death, MI, stroke and ST were adjudicated against original source documents by a clinical event committee (Supplementary Appendix C). Median follow-up duration was 934 (inter-quartile range [IQR]: 669-1243) days.

Categorical variables were compared with the chi-square test. Continuous variables were expressed as mean value \pm standard deviation or median and IQR. Continuous variables were compared using the Student's $t$-test or Wilcoxon rank sum test based on their distributions. Cumulative incidence was estimated by the Kaplan-Meier method and differences were assessed with the log-rank test. We used Cox proportional hazard models to estimate the risk of the successful CTO-PCI group relative to the failed CTO-PCI group adjusting for the differences in patient characteristics and procedural factors as well as medications. In consistent with our previous reports, we selected 34 clinically relevant factors shown in Table 1 as potential independent risk-adjusting variables. ${ }^{11,14}$ Independent correlates for all-cause death were identified by a backward elimination procedure (Supplemental Table 1). The final model incorporated the successful CTO-PCI together with 8 variables remaining after the backward procedure. Adjusted analysis for the other endpoints was performed by using the same 8 risk-adjusting variables as used in the analysis for all-cause death. The continuous variables were dichotomized by clinically meaningful reference values or median values. The effect of the successful CTO-PCI (the successful CTO-PCI 
group compared to the failed CTO-PCI group) was expressed as hazard ratios (HR) and their 95\% confidence intervals (CI). Post-hoc subgroup analysis was also conducted for an exploratory purpose in several clinically relevant subgroups. Statistical analyses were conducted by two physicians (Yamamoto E and Natsuaki M) and by a statistician (Morimoto T) with the use of JMP 10.0 (SAS Institute Inc, Cary, NC) and SAS 9.2 (SAS Institute Inc, Cary, NC) softwares. All the statistical analyses were two-tailed. P values $<0.05$ were considered statistically significant.

\section{Results}

At baseline, acute myocardial infarction, shock at presentation, multivessel disease, moderate to severe mitral regurgitation and dialysis were more prevalent in the failed CTO-PCI group than in the successful CTO-PCI group, while prior MI was more common in the successful CTO-PCI group. Regarding lesion and procedural characteristics, right coronary artery was more frequently targeted in the failed CTO-PCI group than in the successful PCI group. Aspirin and thienopyridine were more frequently used in the successful CTO-PCI group than in the failed CTO-PCI group, while nitrates were more often used in the failed CTO-PCI group (Table 1).

Regarding the procedural complications, coronary perforation was significantly more frequent in the failed CTO-PCI group than in the successful CTO-PCI group. However, there was no significant difference in the incidences of coronary dissection, cardiac tamponade and pericardial drainage between the 2 groups (Table 2). Regarding the in-hospital adverse events, incidence of death and MI tended to be lower in the successful CTO-PCI group. However, there was no significant difference in the incidence of stroke between the 2 groups (Table 2).

The median follow-up durations were 942 (IQR: 679-1245) days in the successful PCI group and 907 
(IQR: 635-1235) days in the failed PCI group. The median duration of dual anti-platelet therapy (DAPT) was significantly different between the successful and failed PCI groups (475 [IQR: 91-874] days vs. 35 [IQR: 1-543] days, $\mathrm{P}<0.0001$ ) (Supplemental Figure 2). Through 3-year follow-up, the cumulative incidence of all-cause death was not significantly different between the successful and failed CTO-PCI groups, while the cumulative incidence of cardiac death was significantly lower in the successful CTO-PCI group than in the failed CTO-PCI group (Table 3, and Figure 2). After adjusting confounders, however, the risks of successful PCI relative to failed PCI for both all-cause death and cardiac death were not significant (Table 3). There was no significant difference in the incidences of MI, stroke and definite ST between the 2 groups (Table 3, and Figure 3). The adjusted risks of successful PCI relative to failed PCI for MI, stroke and definite ST were also not significant (Table 3). Cumulative incidence of CABG was remarkably lower in the successful PCI group than in the failed PCI group. The cumulative incidence of any coronary revascularization was also lower in the successful PCI group than in the failed PCI group (Figure 3). Even after adjusting confounders, the lower risk of successful PCI relative to failed PCI for CABG and any coronary revascularization remained significant (Table 3).

In the post-hoc subgroup analysis, successful PCI was not associated with lower risk for all-cause death in any of the subgroups evaluated. However, successful PCI was associated with lower risk for cardiac death in several subgroups including patients with treated CTO lesion located in left anterior descending artery, patients with single vessel disease, patients without history of heart failure, and patients without diabetic mellitus (Table 4).

\section{Discussion}

The main findings of the current study are as follows: (1) Successful PCI for CTO as compared with failed 
PCI for CTO was not associated with lower risk for 3-year mortality; (2) However, successful PCI for CTO was associated with significantly lower risk for subsequent CABG. CTO-PCI was one of the most challenging fields in the interventional cardiology in the past decade. In the early 2000 s, the success rate of CTO-PCI was $60 \%-70 \%$. ${ }^{9,15}$ Recently, the reported success rate of CTO-PCI has reached $>80 \%$ owing to the development of devices such as tapered wires or micro-catheters as well as advances in operators' techniques such as parallel wire technique and retrograde approach. ${ }^{16-19}$ In consistent to these reports, initial patient success rate of CTO-PCI was $78 \%$ in this study. Successful CTO-PCI is reported to be associated with less subsequent CABG, improvement in left ventricular function and relief of symptoms, which are the main reasons for physicians to perform CTO-PCI. ${ }^{4-6}$ However, the impact of successful PCI for CTO on long-term prognosis is still a matter of debates. ${ }^{8,20-23}$ Most of previous studies evaluating the impact of successful CTO-PCI on long-term outcome adopted the methodology comparing the long-term mortality after successful CTO-PCI with that after failed CTO-PCI. Suero and Hoye reported successful revascularization of CTO were independent predictors of all-cause death. ${ }^{7,15}$ Recently, Mehran reported that successful PCI for CTO was an independent predictor of all-cause death and cardiac death. ${ }^{9}$

In this study, successful PCI for CTO was not associated with lower risk for all-cause death and cardiac death. This result is not consistent to previous reports and there might be several reasons for this discrepancy. First, complications of CTO-PCI might have some influence on the mortality after PCI. Coronary perforation was significantly higher in the failed CTO-PCI group than in the successful CTO-PCI group in this study. However, there were no significant differences in the frequency of severe complications such as cardiac tamponade or pericardial drainage. In contrast, severe complications were more frequent in the failed PCI group than in the 
successful PCI group in previous reports. Mehran et al. reported rate of coronary perforation and residual dissection was $7.4 \%$ and $9.4 \%$ respectively in failed group, and $1.7 \%$ and $4.3 \%$ in success group. ${ }^{9}$ Olivari reported that $2.3 \%$ of patients in the failed CTO-PCI group underwent emergent CABG (no emergent CABG in our study). ${ }^{4}$ Additionally, some reports reported that the incidence of in-hospital MACE was significantly high in failed CTO-PCI group. ${ }^{7,15}$ Second, the difference in the rate of subsequent revascularization after the index PCI might be related to the difference in the outcome. Valenti reported that the incidence of CABG at 1 year was $9.1 \%$ in the failed PCI group, which was remarkably lower compared with current study (17.9\%). ${ }^{23}$ Additionally, among 332 patients in the failed CTO-PCI group, 167 patients underwent repeated revascularization procedures for CTO during 3 years and 113 patients got successful revascularization (PCI: 53 patients, CABG: 60 patients). Subsequent coronary revascularization in patients with failed CTO-PCI might heve attenuated the possible long-term mortality benefit of successful CTO-PCI. Third, the differences in background patient characteristics between the success and failed CTO-PCI groups should be taken in consideration. Fefer et al reported that only $10 \%$ of patients who have CTO lesions underwent CTO-PCI in Canadian multicenter chronic total occlusion registry. ${ }^{24}$ In contrast, 1524 patients out of 2491 patients with CTO lesions (61\%) underwent CTO-PCI in this study. Patients' backgrounds in this study seemed to be worse compared to those reported in previous studies. Additionally, due to relatively high initial success rate, successful CTO-PCI group included many patients with complex clinical and procedural characteristics, who are deemed to have poor long-term prognosis. The success rates of CTO-PCI reported in previous studies suggesting better survival outcome after successful CTO-PCI were lower than the success rate in our study (Mehran: 68.5\%, Jones: 69.6\%, Aziz: 69.4\%). ${ }^{9,10,25}$ It might be postulated that many complex patients 
included in the successful CTO-PCI group in our study could be included in the failed CTO-PCI group in these previous reports, leading to worse survival outcome in the failed CTO-PCI group. Indeed, the failed CTO-PCI group in these previous reports included more patients with older age, ${ }^{23}$ lower left ventricular ejection fraction, and previous $\mathrm{MI}^{10}$ than the successful CTO-PCI group, while in the current study, there was no significant difference between the successful and failed CTO-PCI groups with regard to these factors.

There is no randomized controlled trial comparing PCI plus medical therapy with medical therapy alone in patients with CTO. Given the discrepancy between the current and previous studies in terms of long-term mortality benefit of successful CTO-PCI, it is currently unclear whether successful CTO-PCI could improve long-term mortality. Recently, the Fractional Flow Reserve versus Angiography for Multivessel Evaluation 2 (FAME-2) study demonstrated that in patients with stable coronary artery disease (CAD) and functionally significant stenosis, PCI guided by fractional flow reserve plus the best available medical therapy, as compared with the best available medical therapy alone, decreased the need for urgent revascularization. ${ }^{26}$ However, the benefit of avoiding the need for urgent revascularization could not be expected in stable CAD patients with CTO. A significant proportion of stable CAD patients with CTO are asymptomatic and therefore, we also could not expect symptomatic relief in this patient population. Furthermore, recent prospective randomized trials comparing PCI using DES with CABG in patients with complex multivessel CAD clearly demonstrated better long-term survival with less MI during follow-up with CABG. ${ }^{27-28}$ Therefore, most of the complex multivessel CAD patients with CTO should be referred to CABG surgery, although the above mentioned randomized controlled trials included relatively small number of patients with CTO (6-24\%). According to these recent observations, the appropriate indications for CTO-PCI 
seemed to be limited.

In the exploratory subgroup analysis of this study, successful PCI was associated with lower risk for cardiac death in several subgroups. Safley also reported that successful PCI for CTO was a multivariable predictor for long-term survival in patients with treated LAD CTO lesion. ${ }^{29}$ Therefore, it is possible that successful CTO-PCI could be associated with improved survival outcome in some selected subgroups of patients. However, we should be very careful in interpreting the results of the subgroup analysis in the overall negative study.

Prospective randomized trials comparing PCI plus medical therapy with medical therapy alone in patients with CTO, adequately powered for evaluating long-term mortality, are absolutely required to define the indication of PCI for CTO. Drug-Eluting Stent Implantation Versus Optimal Medical Treatment in Patients With Chronic Total Occlusion (DECISION-CTO) trial is currently ongoing.

There are several limitations in this study. This is an observational study and the baseline patient characteristics were significantly different between the 2 groups. Despite statistical adjustment, it was not certain whether the mortality outcome was related to the successful CTO-PCI itself or was related to the presence of unmeasured confounders. Second, the current analysis was obviously underpowered in evaluating long-term mortality, although we enrolled relatively large number of patients with CTO as compared with previous studies. Third, there were no criteria to perform PCI for CTO lesions and the decision was left to each attending physician. Therefore, the conclusions of the current study could not be extrapolated to CTO-PCI in general. Fourth, patients with failed CTO-PCI are not equivalent to those patients with CTO who were managed with medical therapy alone.

Fifth, the skill for CTO-PCI is demanding and therefore, procedural outcome as well as long-term outcome could 
be different according to the centers or operators. Sixth, the low treatment rate of statins, beta blockers, angiotensin converting enzyme inhibitors and angiotensin II receptor blockers may have significant impact on the overall event rates at follow-up. Seventh, successful intervention of non-CTO lesions may lead to difficulty in detecting a difference between the 2 groups. Furthermore, high rate of subsequent coronary revascularization in patients with failed CTO-PCI might have attenuated the possible long-term mortality benefit of successful CTO-PCI in this study.

Eighth, the duration of DAPT was different between the successful and failed PCI group, which might have influenced the long-term outcome. Finally, there was no information about the viability or ischemia in the myocardial territory subtended by the targeted lesions in this study.

\section{Acknowledgement}

We appreciate the collaboration of the co-investigators in the CREDO-Kyoto PCI/CABG Registry

Cohort-2. This study was supported by the Pharmaceuticals and Medical Devices Agency (PMDA) in Japan.

\section{Disclosures}

None 
1. Rathore S, Matsuo H, Terashima M, Kinoshita Y, Kimura M, Tsuchikane E, Nasu K, Ehara M, Asakura Y, Katoh O, Suzuki T. Procedural and in-hospital outcomes after percutaneous coronary intervention for chronic total occlusions of coronary arteries 2002 to 2008: Impact of novel guidewire techniques. JACC Cardiovasc Interv 2009;2:489-497

2. Colmenarez HJ, Escaned J, Fernandez C, Lobo L, Cano S, del Angel JG, Alfonso F, Jimenez P, Banuelos C, Gonzalo N, Garcia E, Hernandez R, Macaya C. Efficacy and safety of drug-eluting stents in chronic total coronary occlusion recanalization: A systematic review and meta-analysis. $J$ Am Coll Cardiol 2010;55:1854-1866

3. Marroquin OC, Selzer F, Mulukutla SR, Williams DO, Vlachos HA, Wilensky RL, Tanguay JF, Holper EM, Abbott JD, Lee JS, Smith C, Anderson WD, Kelsey SF, Kip KE. A comparison of bare-metal and drug-eluting stents for off-label indications. N Engl J Med 2008;358:342-352

4. Olivari Z, Rubartelli P, Piscione F, Ettori F, Fontanelli A, Salemme L, Giachero C, Di Mario C, Gabrielli G, Spedicato L, Bedogni F. Immediate results and one-year clinical outcome after percutaneous coronary interventions in chronic total occlusions: Data from a multicenter, prospective, observational study (TOAST-GISE). J Am Coll Cardiol 2003;41:1672-1678

5. Sirnes PA, Myreng Y, Molstad P, Bonarjee V, Golf S. Improvement in left ventricular ejection fraction and wall motion after successful recanalization of chronic coronary occlusions. Eur Heart J 1998;19:273-281

6. Grantham JA, Jones PG, Cannon L, Spertus JA. Quantifying the early health status benefits of successful chronic total occlusion recanalization: Results from the flowcardia's approach to chronic total occlusion 
recanalization (FACTOR) trial. Circ Cardiovasc Qual Outcomes 2010;3:284-290

7. Suero JA, Marso SP, Jones PG, Laster SB, Huber KC, Giorgi LV, Johnson WL, Rutherford BD. Procedural outcomes and long-term survival among patients undergoing percutaneous coronary intervention of a chronic total occlusion in native coronary arteries: A 20-year experience. J Am Coll Cardiol 2001;38:409-414

8. Joyal D, Afilalo J, Rinfret S. Effectiveness of recanalization of chronic total occlusions: A systematic review and meta-analysis. Am Heart J 2010;160:179-187

9. Mehran R, Claessen BE, Godino C, Dangas GD, Obunai K, Kanwal S, Carlino M, Henriques JP, Di Mario C, Kim YH, Park SJ, Stone GW, Leon MB, Moses JW, Colombo A. Long-term outcome of percutaneous coronary intervention for chronic total occlusions. JACC Cardiovasc Interv 2011;4:952-961

10. Jones DA, Weerackody R, Rathod K, Behar J, Gallagher S, Knight CJ, Kapur A, Jain AK, Rothman MT, Thompson CA, Mathur A, Wragg A, Smith EJ. Successful recanalization of chronic total occlusions is associated with improved long-term survival. JACC Cardiovasc Interv 2012;5:380-388

11. Kimura T, Morimoto T, Furukawa Y, Nakagawa Y, Kadota K, Iwabuchi M, Shizuta S, Shiomi H, Tada T, Tazaki J, Kato Y, Hayano M, Abe M, Tamura T, Shirotani M, Miki S, Matsuda M, Takahashi M, Ishii K, Tanaka M, Aoyama T, Doi O, Hattori R, Tatami R, Suwa S, Takizawa A, Takatsu Y, Takahashi M, Kato H, Takeda T, Lee JD, Nohara R, Ogawa H, Tei C, Horie M, Kambara H, Fujiwara H, Mitsudo K, Nobuyoshi M, Kita T. Long-term safety and efficacy of sirolimus-eluting stents versus bare-metal stents in real world clinical practice in Japan. Cardiovasc Interv and Ther 2011;26:234-245.

12. Serruys PW, Ong AT, van Herwerden LA, Sousa JE, Jatene A, Bonnier JJ, Schonberger JP, Buller N, Bonser R, 
Disco C, Backx B, Hugenholtz PG, Firth BG, Unger F. Five-year outcomes after coronary stenting versus bypass surgery for the treatment of multivessel disease: the final analysis of the Arterial Revascularization Therapies Study (ARTS) randomized trial. J Am Coll Cardiol 2005;46:575-581.

13. Mauri L, Hsieh WH, Massaro JM, Ho KK, D'Agostino R, Cutlip DE. Stent thrombosis in randomized clinical trials of drug-eluting stents N Engl J Med. 2007 Mar 8;356(10):1020-1029

14. Natsuaki M, Nakagawa Y, Morimoto T, Ono K, Shizuta S, Furukawa Y, Kadota K, Iwabuchi M, Kato Y, Suwa S, Inada T, Doi O, Takizawa A, Nobuyoshi M, Kita T, Kimura T. Impact of statin therapy on late target lesion revascularization after sirolimus-eluting stent implantation (from the CREDO-Kyoto Registry Cohort-2). Am J Cardiol 2012;109:1387-1396

15. Hoye A, van Domburg RT, Sonnenschein K, Serruys PW. Percutaneous coronary intervention for chronic total occlusions: The Thoraxcenter experience 1992-2002. Eur Heart J 2005;26:2630-2636

16. Galassi AR, Tomasello SD, Reifart N, Werner GS, Sianos G, Bonnier H, Sievert H, Ehladad S, Bufe A, Shofer J, Gershlick A, Hildick-Smith D, Escaned J, Erglis A, Sheiban I, Thuesen L, Serra A, Christiansen E, Buettner A, Costanzo L, Barrano G, Di Mario C. In-hospital outcomes of percutaneous coronary intervention in patients with chronic total occlusion: Insights from the ERCTO (European Registry of Chronic Total Occlusion) registry. EuroIntervention 2011;7:472-479

17. Morino Y, Kimura T, Hayashi Y, Muramatsu T, Ochiai M, Noguchi Y, Kato K, Shibata Y, Hiasa Y, Doi O, Yamashita T, Morimoto T, Abe M, Hinohara T, Mitsudo K. In-hospital outcomes of contemporary percutaneous coronary intervention in patients with chronic total occlusion insights from the j-CTO registry (multicenter 
CTO registry in Japan). JACC Cardiovasc Interv 2010;3:143-151

18. Mitsudo K, Yamashita T, Asakura Y, Muramatsu T, Doi O, Shibata Y, Morino Y. Recanalization strategy for chronic total occlusions with tapered and stiff-tip guidewire. The results of CTO new technique for standard procedure (conquest) trial. J Invasive Cardiol 2008;20:571-577

19. Sianos G, Barlis P, Di Mario C, Papafaklis MI, Buttner J, Galassi AR, Schofer J, Werner G, Lefevre T, Louvard Y, Serruys PW, Reifart N. European experience with the retrograde approach for the recanalisation of coronary artery chronic total occlusions. A report on behalf of the euroCTO club. EuroIntervention 2008;4:84-92

20. de Labriolle A, Bonello L, Roy P, Lemesle G, Steinberg DH, Xue Z, Kaneshige K, Suddath WO, Satler LF, Kent KM, Pichard AD, Lindsay J, Waksman R. Comparison of safety, efficacy, and outcome of successful versus unsuccessful percutaneous coronary intervention in "true" chronic total occlusions. Am $J$ Cardiol 2008;1:1175-1178

21. Jolicoeur EM, Sketch MJ, Wojdyla DM, Javaheri SP, Nosib S, Lokhnygina Y, Patel MR, Shaw LK, Tcheng JE. Percutaneous coronary interventions and cardiovascular outcomes for patients with chronic total occlusions. Catheter Cardiovasc Interv 2012;79:603-612

22. Lee SW, Lee JY, Park DW, Kim YH, Yun SC, Kim WJ, Suh J, Cho YH, Lee NH, Kang SJ, Lee CW, Park SW, Park SJ. Long-term clinical outcomes of successful versus unsuccessful revascularization with drug-eluting stents for true chronic total occlusion. Catheter Cardiovasc Interv 2011;78:346-353.

23. Valenti R, Migliorini A, Signorini U, Vergara R, Parodi G, Carrabba N, Cerisano G, Antoniucci D. Impact of complete revascularization with percutaneous coronary intervention on survival in patients with at least 
one chronic total occlusion. Eur Heart J 2008;29:2336-2342

24. Fefer P, Knudtson ML, Cheema AN, Galbraith PD, Osherov AB, Yalonetsky S, Gannot S, Samuel M, Weisbrod M, Bierstone D, Sparkes JD, Wright GA, Strauss BH. Current perspectives on coronary chronic total occlusions: The Canadian multicenter chronic total occlusions registry. J Am Coll Cardiol 2012;59:991-997

25. Aziz S, Stables RH, Grayson AD, Perry RA, Ramsdale DR. Percutaneous coronary intervention for chronic total occlusions: Improved survival for patients with successful revascularization compared to a failed procedure. Catheter Cardiovasc Interv 2007;70:15-

26. De Bruyne B, Pijls NH, Kalesan B, Barbato E, Tonino PA, Piroth Z, Jagic N, Möbius-Winkler S, Rioufol G, Witt N, Kala P, MacCarthy P, Engström T, Oldroyd KG,Mavromatis K, Manoharan G, Verlee P, Frobert O, Curzen N, Johnson JB, Jüni P, Fearon WF; FAME 2 Trial Investigators.

Fractional flow reserve-guided PCI versus medical therapy in stable coronary disease. $N$ Engl $J$ Med 2012;367:991-1001

27. Serruys PW, Morice MC, Kappetein AP, Colombo A, Holmes DR, Mack MJ, Ståhle E, Feldman TE, van den Brand M, Bass EJ, Van Dyck N, Leadley K, Dawkins KD, Mohr FW; SYNTAX Investigators. Percutaneous coronary intervention versus coronary-artery bypass grafting for severe coronary artery disease. $N$ Engl J Med 2009;360:961-72.

28. Bansilal S, Farkouh ME, Hueb W, Ogdie M, Dangas G, Lansky AJ, Cohen DJ, Magnuson EA, Ramanathan K, Tanguay JF, Muratov V, Sleeper LA, Domanski M,Bertrand ME, Fuster V. The Future REvascularization Evaluation in patients with Diabetes mellitus: optimal management of Multivessel disease (FREEDOM) trial: 
clinical and angiographic profile at study entry. Am Heart J 2012;164:591-599.

29. Safley DM, House JA, Marso SP, Grantham JA, Rutherford BD. Improvement in survival following successful percutaneous coronary intervention of coronary chronic total occlusions: Variability by target vessel. JACC Cardiovasc Interv 2008;1:295-302 


\section{Figure legends}

\section{Figure 1.}

Study flow chart.

PCI, percutaneous coronary intervention; CABG, coronary artery bypass grafting; CTO, chronic total occlusion.

\section{Figure 2.}

Cumulative incidences of (A) all-cause death and (B) cardiac death: the success PCI vs. failed PCI group.

PCI, percutaneous coronary intervention;

\section{Figure 3.}

Cumulative incidences of (A) myocardial infarction, (B) stroke, (C) CABG and (D) any coronary revascularization: the success PCI vs. failed PCI group.

PCI, percutaneous coronary intervention; CABG, coronary artery bypass grafting. 
Table 1. Baseline Characteristics: Successful versus Failed PCI for Chronic Total Occlusion

\begin{tabular}{|c|c|c|c|}
\hline Variable & $\begin{array}{l}\text { Success } \\
(\mathrm{N}=1192)\end{array}$ & $\begin{array}{l}\text { Failure } \\
(\mathrm{N}=332)\end{array}$ & $\mathrm{P}$ value \\
\hline \multicolumn{4}{|l|}{ (A) Clinical characteristics } \\
\hline Age (years) & $66.9 \pm 10.8$ & $66.2 \pm 10.7$ & 0.32 \\
\hline Age $>=75^{*}$ & $324(27 \%)$ & $80(24 \%)$ & 0.26 \\
\hline Male* & $926(78 \%)$ & $253(76 \%)$ & 0.57 \\
\hline BMI $\left(\mathrm{kg} / \mathrm{m}^{2}\right)$ & $24.2 \pm 3.6$ & $24.3 \pm 3.6$ & 0.82 \\
\hline $\mathrm{BMI}<25.0 * *$ & $762(64 \%)$ & $205(62 \%)$ & 0.47 \\
\hline Acute myocardial infarction* & $101(8.5 \%)$ & $63(19 \%)$ & $<0.0001$ \\
\hline Hypertension* & $989(83 \%)$ & $290(87 \%)$ & 0.055 \\
\hline Diabetes mellitus & $498(42 \%)$ & $141(42 \%)$ & 0.82 \\
\hline on insulin therapy* & $114(9.6 \%)$ & $32(9.6 \%)$ & 0.97 \\
\hline Current smoker* & $389(33 \%)$ & $118(36 \%)$ & 0.32 \\
\hline Heart failure $* *$ & $258(22 \%)$ & $81(24 \%)$ & 0.29 \\
\hline Shock at presentation* & $25(2.1 \%)$ & $19(5.7 \%)$ & 0.001 \\
\hline Multivessel coronary disease $* *$ & $853(72 \%)$ & $277(83 \%)$ & $<0.0001$ \\
\hline Mitral regurgitation grade $3 / 4 *$ & $65(7.1 \%)$ & $31(13 \%)$ & 0.005 \\
\hline Ejection fraction (\%) & $55.4 \pm 13.4$ & $54.3 \pm 14.6$ & 0.23 \\
\hline Prior myocardial infarction* & $381(32 \%)$ & $80(24 \%)$ & 0.006 \\
\hline Prior stroke* & $178(15 \%)$ & $56(17 \%)$ & 0.39 \\
\hline Peripheral vascular disease* & $93(7.8 \%)$ & $27(8.1 \%)$ & 0.84 \\
\hline eGFR $<30$, not on dialysis** & $45(3.8 \%)$ & $13(3.9 \%)$ & 0.91 \\
\hline Dialysis** & $43(3.6 \%)$ & $27(8.1 \%)$ & 0.0005 \\
\hline Atrial fibrillation* & $99(8.3 \%)$ & $26(7.8 \%)$ & 0.78 \\
\hline Anemia (hemoglobin $<11 \mathrm{~g} / \mathrm{dl}$ ) $* *$ & $131(11 \%)$ & $40(12 \%)$ & 0.59 \\
\hline Platelet $<100^{*} 10^{9} / \mathrm{L}^{*}$ & $17(1.4 \%)$ & $4(1.2 \%)$ & 0.76 \\
\hline Chronic obstructive pulmonary disease* & $35(2.9 \%)$ & $11(3.3 \%)$ & 0.72 \\
\hline Liver cirrhosis* & $27(2.3 \%)$ & $8(2.4 \%)$ & 0.88 \\
\hline Malignancy* & $80(6.7 \%)$ & $26(7.8 \%)$ & 0.48 \\
\hline \multicolumn{4}{|l|}{ (B) Procedural characteristics } \\
\hline Number of target lesions & $1.8 \pm 0.9$ & $1.8 \pm 0.9$ & 0.96 \\
\hline Number of target vessels & $1.6 \pm 0.7$ & $1.6 \pm 0.7$ & 0.88 \\
\hline Number of CTO vessels & $1.1 \pm 0.4$ & $1.2 \pm 0.4$ & 0.4 \\
\hline Number of target CTO vessels & $1.0 \pm 0.2$ & $1.0 \pm 0.1$ & 0.053 \\
\hline
\end{tabular}


Left anterior descending

Proximal left anterior descending*

Left circumflex

Right

Unprotected left main*

Contrast media volume

(C) Baseline medication

Antiplatelet therapy

Thienopyridine

$$
\begin{aligned}
& \text { Ticlopidine } \\
& \text { Clopidogrel }
\end{aligned}
$$

Aspirin

Cilostazol*

Other medications

Statin**

Beta-blockers*

ACE-I / ARB**

Nitrates*

Calcium channel blockers*

Nicorandil*

Warfarin*

Proton pump inhibitors*

H2-blockers*

$$
\begin{gathered}
505(42 \%) \\
458(38 \%) \\
346(29 \%) \\
507(43 \%) \\
1(0.1 \%)
\end{gathered}
$$

$211(150-303)$

$$
\begin{gathered}
121(36 \%) \\
111(33 \%) \\
88(27 \%) \\
176(53 \%) \\
0
\end{gathered}
$$

207 (146-300)
0.053

0.1

0.37

0.0007

0.6

0.26

$\begin{array}{ccc}1172(98 \%) & 303(91 \%) & <0.0001 \\ 1058(91 \%) & 279(92 \%) & 0.42 \\ 110(9.4 \%) & 24(7.9 \%) & \\ 1181(99 \%) & 322(97 \%) & 0.004 \\ 140(12 \%) & 48(14 \%) & 0.18\end{array}$

$\begin{array}{lll}633(53 \%) & 160(48 \%) & 0.11 \\ 379(32 \%) & 124(37 \%) & 0.06 \\ 678(57 \%) & 195(59 \%) & 0.55 \\ 475(40 \%) & 155(47 \%) & 0.03 \\ 488(41 \%) & 140(42 \%) & 0.69 \\ 303(25 \%) & 93(28 \%) & 0.34 \\ 99(8.3 \%) & 28(8.4 \%) & 0.94 \\ 278(23 \%) & 71(21 \%) & 0.46 \\ 267(22 \%) & 86(26 \%) & 0.18\end{array}$

Values are expressed as mean \pm SD or median (inter-quartile range).

BMI indicated body mass index; eGFR, estimated glomerular filtration rate; CTO, chronic total occlusion; ACE-I, angiotensin converting enzyme inhibitors; ARB, angiotensin II receptor blockers.

* Potential independent variables selected for Cox proportional hazard models.

** Risk-adjusting variables. 
Table 2. Procedural Complications and In-hospital Adverse Events

\begin{tabular}{lccc}
\hline Variable & $\begin{array}{c}\text { Success } \\
(\mathrm{N}=1192)\end{array}$ & $\begin{array}{c}\text { Failure } \\
(\mathrm{N}=332)\end{array}$ & P value \\
\hline Procedural Complications & & & \\
$\quad$ Coronary dissection & $12(1.0 \%)$ & $5(1.5 \%)$ & 0.44 \\
Coronary perforation & $7(0.6 \%)$ & $10(3.0 \%)$ & 0.0002 \\
Cardiac tamponade & $3(0.3 \%)$ & $2(0.6 \%)$ & 0.32 \\
Pericardial drainage & 0 & $1(0.3 \%)$ & 0.06 \\
& & & \\
In-hospital adverse events & & & 0.053 \\
Death & $17(1.4 \%)$ & $10(3.0 \%)$ & 0.053 \\
Myocardial infarction & $10(0.8 \%)$ & $7(2.1 \%)$ & 0.66 \\
Stroke & $5(0.4 \%)$ & $2(0.6 \%)$ & 0.06 \\
Coronary bypass & 0 & $1(0.3 \%)$ & 0.07 \\
Any coronary revascularization & $13(1.1 \%)$ & $8(2.4 \%)$ & \\
\hline
\end{tabular}


Table 3. Unadjusted and Adjusted Risk for Clinical Events

\begin{tabular}{|c|c|c|c|c|c|c|}
\hline Variable & $\begin{array}{c}\text { Success } \\
\mathrm{N} \text { of events / } \mathrm{N} \text { of } \\
\text { patients } \\
\text { (Incidence) }\end{array}$ & $\begin{array}{c}\text { Failure } \\
\mathrm{N} \text { of events } / \mathrm{N} \text { of } \\
\text { patients } \\
\text { (Incidence) }\end{array}$ & $\begin{array}{l}\text { Unadjusted } \\
\text { HR }(95 \% \mathrm{CI})\end{array}$ & $P$ value & $\begin{array}{c}\text { Adjusted } \\
\text { HR }(95 \% \mathrm{CI})\end{array}$ & $P$ value \\
\hline All-cause death & $92 / 1192(9.0 \%)$ & $35 / 332(13.1 \%)$ & $\begin{array}{c}0.77 \\
(0.53-1.30)\end{array}$ & 0.18 & $0.93(0.64-1.37)$ & 0.69 \\
\hline Cardiac death & $46 / 1192(4.5 \%)$ & $24 / 332(8.4 \%)$ & $\begin{array}{c}0.58 \\
(0.37-0.95)\end{array}$ & 0.03 & $0.71(0.44-1.16)$ & 0.16 \\
\hline Myocardial infarction & $30 / 1192(3.2 \%)$ & $15 / 332(5.5 \%)$ & $\begin{array}{c}0.54 \\
(0.30-1.01)\end{array}$ & 0.052 & $0.60(0.33-1.13)$ & 0.11 \\
\hline Stroke & $52 / 1192(5.0 \%)$ & $19 / 332(6.3 \%)$ & $\begin{array}{c}0.71 \\
(0.43-1.21)\end{array}$ & 0.2 & $0.81(0.49-1.40)$ & 0.45 \\
\hline Coronary bypass & $20 / 1192(1.8 \%)$ & $60 / 332(19.6 \%)$ & $\begin{array}{c}0.08 \\
(0.05-0.13)\end{array}$ & $<0.0001$ & $0.09(0.06-0.15)$ & $<0.0001$ \\
\hline $\begin{array}{l}\text { Any coronary } \\
\text { revascularization }\end{array}$ & $389 / 1192(35.5 \%)$ & $60 / 332(55.7 \%)$ & $\begin{array}{c}0.46 \\
(0.38-0.55)\end{array}$ & $<0.0001$ & $0.50(0.41-0.60)$ & $<0.0001$ \\
\hline
\end{tabular}

Cumulative incidence was estimated by the Kaplan-Meier method.

HR indicated hazard ratio; CI, confidence interval. 
Table 4. Subgroup Analysis for All-cause Death and Cardiac Death at 3 Years

\begin{tabular}{|c|c|c|c|c|}
\hline Variable & $\begin{array}{c}\text { Success } \\
\mathrm{N} \text { of events / } \mathrm{N} \text { of } \\
\text { patients } \\
\text { (Incidence) }\end{array}$ & $\begin{array}{c}\text { Failure } \\
\mathrm{N} \text { of events } / \mathrm{N} \text { of } \\
\text { patients } \\
\text { (Incidence) }\end{array}$ & $\begin{array}{l}\text { Unadjusted HR } \\
\quad(95 \% \mathrm{CI})\end{array}$ & $P$ value \\
\hline \multicolumn{5}{|l|}{ All-cause death } \\
\hline Multivessel coronary disease & $79 / 853(10.8 \%)$ & $30 / 277(13.7 \%)$ & $0.92(0.62-1.40)$ & 0.69 \\
\hline Single vessel coronary disease & $13 / 399(4.6 \%)$ & $5 / 55(9.9 \%)$ & $0.40(0.15-1.23)$ & 0.06 \\
\hline History of heart failure & $50 / 258(22.1 \%)$ & $16 / 81(24.5 \%)$ & $1.01(0.60-1.84)$ & 0.98 \\
\hline No history of heart failure & $42 / 934(5.4 \%)$ & $19 / 251(9.5 \%)$ & $0.63(0.29-1.07)$ & 0.07 \\
\hline Left anterior descending & $35 / 505(8.3 \%)$ & $14 / 121(13.3 \%)$ & $0.67(0.38-1.28)$ & 0.19 \\
\hline Non-left anterior descending & $57 / 687(9.6 \%)$ & $21 / 211(13.0 \%)$ & $0.83(0.52-1.37)$ & 0.45 \\
\hline Diabetes mellitus & $48 / 498(11.4 \%)$ & $14 / 141(11.3 \%)$ & $0.99(0.57-1.82)$ & 0.97 \\
\hline Non-diabetes mellitus & $44 / 694(7.4 \%)$ & $21 / 191(14.5 \%)$ & $0.62(0.38-1.04)$ & 0.06 \\
\hline \multicolumn{5}{|l|}{ Cardiac death } \\
\hline Multivessel coronary disease & $40 / 853(5.6 \%)$ & $19 / 277(8.1 \%)$ & $0.76(0.45-1.30)$ & 0.3 \\
\hline Single vessel coronary disease & $6 / 399(1.8 \%)$ & $5 / 55(9.9 \%)$ & $0.20(0.06-0.68)$ & 0.01 \\
\hline History of heart failure & $35 / 258(15.6 \%)$ & $12 / 81(17.6 \%)$ & $0.94(0.51-1.88)$ & 0.86 \\
\hline No history of heart failure & $11 / 934(1.5 \%)$ & $12 / 251(5.5 \%)$ & $0.32(0.16-0.68)$ & 0.004 \\
\hline Left anterior descending & $15 / 505(3.7 \%)$ & $10 / 121(9.2 \%)$ & $0.43(0.21-0.97)$ & 0.04 \\
\hline Non-left anterior descending & $14 / 687(5.1 \%)$ & $14 / 211(8.0 \%)$ & $0.70(0.39-1.33)$ & 0.27 \\
\hline Diabetes mellitus & $26 / 498(6.2 \%)$ & $11 / 141(8.4 \%)$ & $0.71(0.38-1.45)$ & 0.33 \\
\hline Non-diabetes mellitus & $20 / 694(3.3 \%)$ & $13 / 191(8.4 \%)$ & $0.47(0.24-0.95)$ & 0.04 \\
\hline
\end{tabular}


Figure 1.

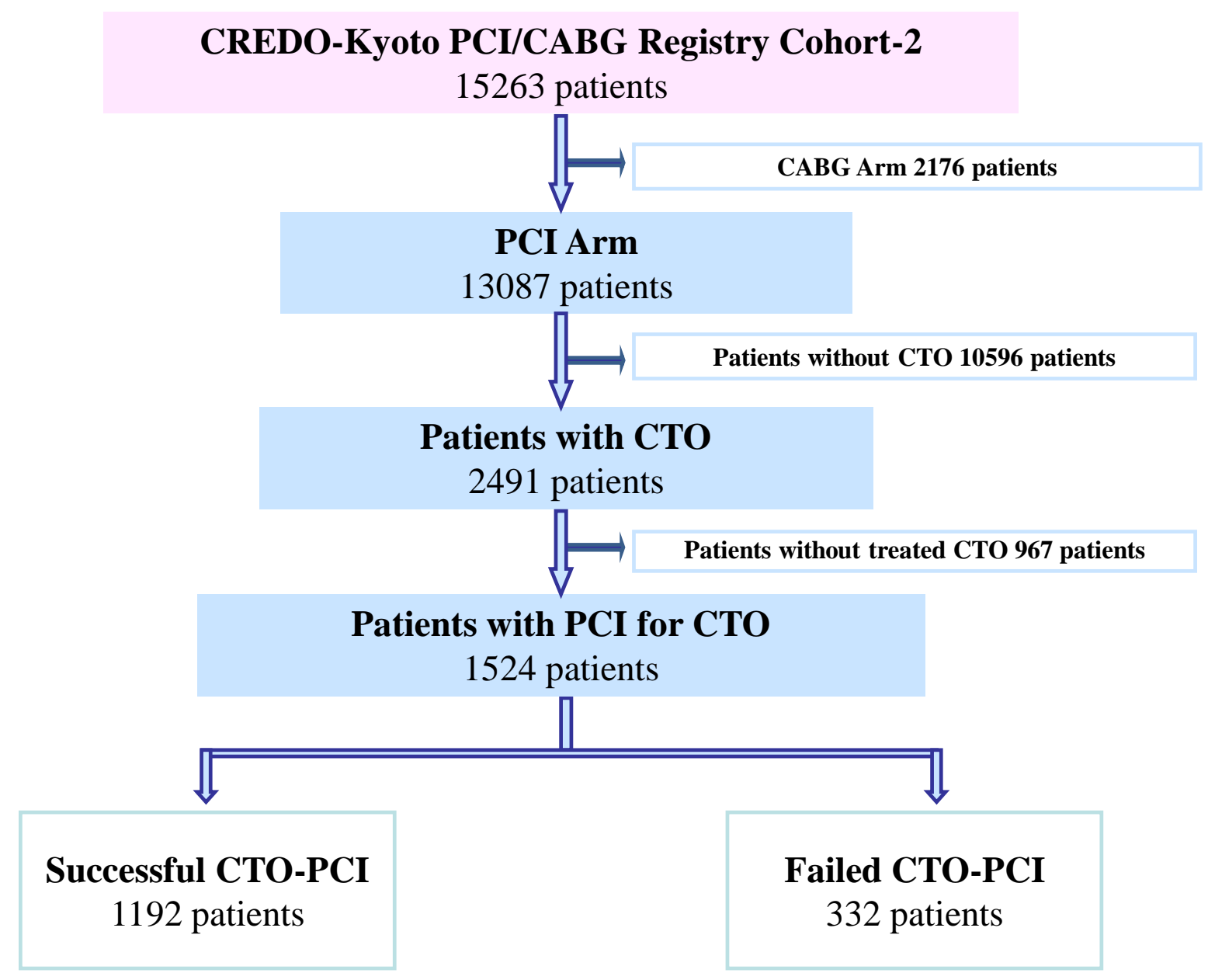


Figure 2.

(A) All-cause death

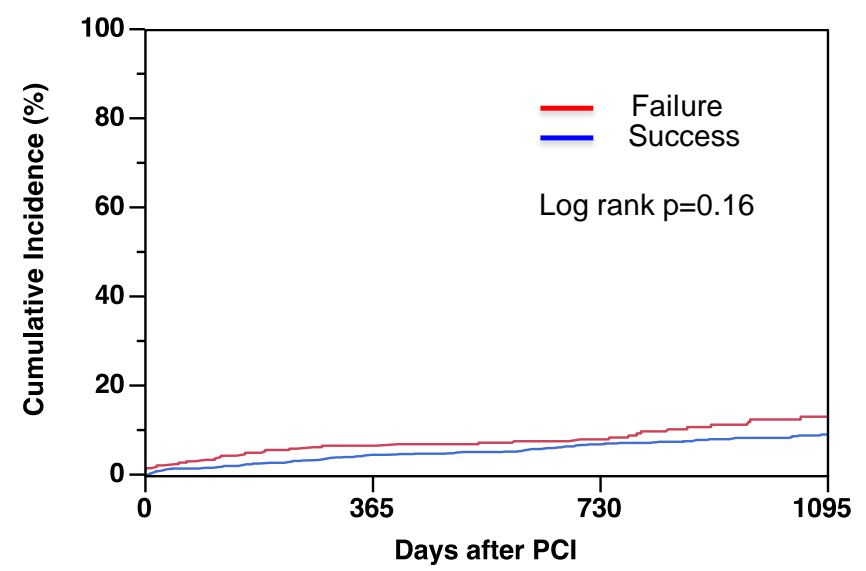

\begin{tabular}{lccccc} 
Interval & 0days & 30days & 1year & 2years & 3years \\
\hline Success & & & & & \\
\hline Cumulative incidence & $1.3 \%$ & $4.5 \%$ & $6.8 \%$ & $9.0 \%$ \\
N of patients with event & 15 & 53 & 77 & 92 \\
N of patients at risk & 1192 & 1175 & 1108 & 825 & 453 \\
\hline Failure & & & & & \\
\hline Cumulative incidence & & $2.4 \%$ & $6.5 \%$ & $8.0 \%$ & $13.1 \%$ \\
N of patients with event & & 8 & 21 & 25 & 35 \\
N of patietns at risk & 332 & 315 & 289 & 222 & 128
\end{tabular}

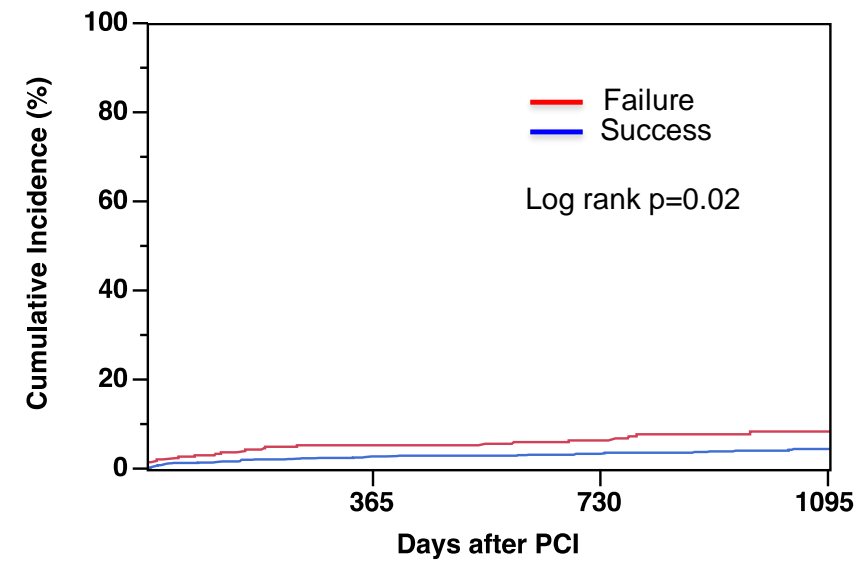

(B) Cardiac death

\begin{tabular}{lccccc} 
Interval & Odays & 30days & 1year & 2years & 3years \\
\hline Success & & & & & \\
\hline Cumulative incidence & & $1.2 \%$ & $2.8 \%$ & $3.4 \%$ & $4.5 \%$ \\
N of patients with event & & 14 & 33 & 39 & 46 \\
N of patients at risk & 1192 & 1175 & 1108 & 825 & 453 \\
\hline Failure & & & & & \\
\hline Cumulative incidence & & $2.4 \%$ & $5.3 \%$ & $6.4 \%$ & $8.4 \%$ \\
N of patients with event & & 8 & 17 & 20 & 24 \\
N of patients at risk & 332 & 315 & 289 & 222 & 128
\end{tabular}


Figure 3.

(A) Myocardial infarction

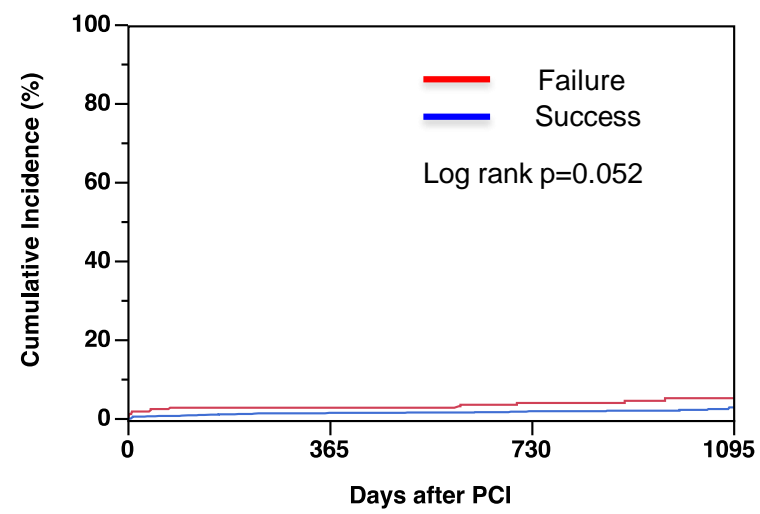

\begin{tabular}{|c|c|c|c|c|c|}
\hline Interval & Odays & 30days & 1year & 2years & 3years \\
\hline \multicolumn{6}{|l|}{ Success } \\
\hline Cumulative incidence & & $0.8 \%$ & $1.8 \%$ & $2.2 \%$ & $3.2 \%$ \\
\hline $\mathrm{N}$ of patients with event & & 10 & 21 & 25 & 30 \\
\hline $\mathrm{N}$ of patients at risk & 1192 & 1166 & 1089 & 808 & 442 \\
\hline \multicolumn{6}{|l|}{ Failure } \\
\hline Cumulative incidence & & $2.2 \%$ & $3.1 \%$ & $4.3 \%$ & $5.5 \%$ \\
\hline $\mathrm{N}$ of patients with event & & 7 & 10 & 13 & 15 \\
\hline $\mathrm{N}$ of patients at risk & 332 & 309 & 281 & 215 & 124 \\
\hline
\end{tabular}

(C) CABG

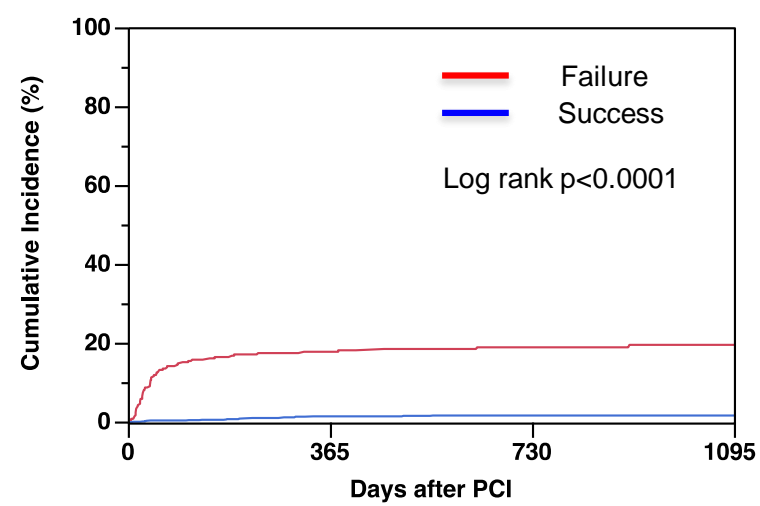

\begin{tabular}{lccccc} 
Interval & 0days & 30days & 1year & 2years & 3years \\
\hline Success & & & & & \\
\hline Cumulative incidence & & $0.3 \%$ & $1.6 \%$ & $1.8 \%$ & $1.8 \%$ \\
N of patients with event & 3 & 18 & 20 & 20 \\
N of patients at risk & 1192 & 1172 & 1089 & 808 & 444 \\
\hline Failure & & & & & \\
\hline Cumulative incidence & & $8.5 \%$ & $17.9 \%$ & $19.0 \%$ & $19.6 \%$ \\
N of patients with event & & 27 & 56 & 59 & 60 \\
N of patients at risk & 332 & 289 & 236 & 174 & 97
\end{tabular}

(B) Stroke

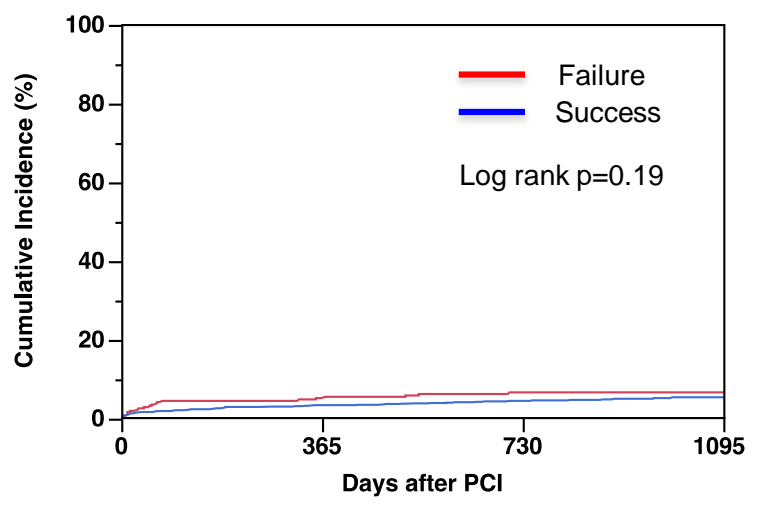

\begin{tabular}{|c|c|c|c|c|c|}
\hline Interval & Odays & 30days & 1year & 2years & 3years \\
\hline \multicolumn{6}{|l|}{ Success } \\
\hline Cumulative incidence & & $1.2 \%$ & $3.0 \%$ & $4.1 \%$ & $5.0 \%$ \\
\hline $\mathrm{N}$ of patients with event & & 14 & 35 & 46 & 52 \\
\hline $\mathrm{N}$ of patients at risk & 1192 & 1163 & 1085 & 803 & 439 \\
\hline \multicolumn{6}{|l|}{ Failure } \\
\hline Cumulative incidence & & $1.9 \%$ & $5.1 \%$ & $6.3 \%$ & $6.3 \%$ \\
\hline $\mathrm{N}$ of patients with event & & 6 & 16 & 19 & 19 \\
\hline $\mathrm{N}$ of patients at risk & 332 & 310 & 278 & 209 & 121 \\
\hline
\end{tabular}

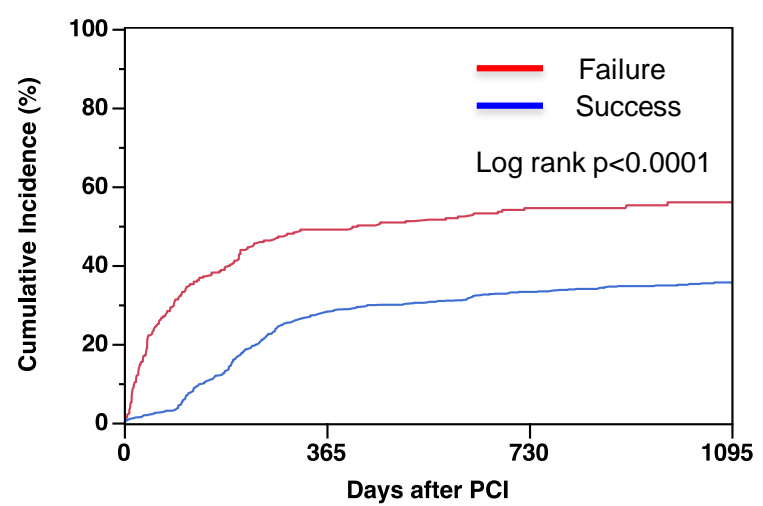

\begin{tabular}{lccccc} 
Interval & Odays & 30days & 1year & 2years & 3years \\
\hline Success & & & & & \\
\hline Cumulative incidence & $1.5 \%$ & $28.1 \%$ & $33.1 \%$ & $35.5 \%$ \\
$\mathrm{~N}$ of patients with event & 18 & 321 & 373 & 389 \\
$\mathrm{~N}$ of patients at risk & 1192 & 1159 & 798 & 570 & 307 \\
\hline Failure & & $15.1 \%$ & $48.8 \%$ & $54.2 \%$ & $55.7 \%$ \\
\hline Cumulative incidence & 48 & 151 & 165 & 167 \\
$\mathrm{~N}$ of patients with event & & 268 & 146 & 97 & 50
\end{tabular}




\section{SUPPLEMENTAL MATERIAL}

Supplemental Table 1. Unadjusted and Adjusted Analysis for All-cause Death

\begin{tabular}{|c|c|c|c|c|}
\hline Variable & $\begin{array}{l}\text { Unadjusted } \\
\text { HR }(95 \% \mathrm{CI})\end{array}$ & $\mathrm{P}$ value & $\begin{array}{c}\text { Adjusted } \\
\text { HR }(95 \% \mathrm{CI})\end{array}$ & $P$ value \\
\hline CTO Success & $0.77(0.53-1.13)$ & 0.18 & $0.93(0.64-1.37)$ & 0.69 \\
\hline Age $>=75$ & $2.55(1.83-3.54)$ & $<0.0001$ & & \\
\hline Male & $1.17(0.79-1.81)$ & 0.44 & & \\
\hline BMI $<25.0$ & $2.85(1.89-4.49)$ & $<0.0001$ & $2.09(1.37-3.33)$ & 0.0005 \\
\hline Acute myocardial infarction & $2.29(1.50-3.39)$ & 0.0003 & & \\
\hline Hypertension & $1.02(0.67-1.64)$ & 0.92 & & \\
\hline Diabetes mellitus on insulin therapy & $2.03(1.29-3.07)$ & 0.003 & & \\
\hline Current smorker & $0.80(0.55-1.14)$ & 0.21 & & \\
\hline Heare failure & $3.79(2.73-5.27)$ & $<0.0001$ & $3.27(2.32-4.59)$ & $<0.0001$ \\
\hline Shock at presentation & $6.91(4.08-11.03)$ & $<0.0001$ & & \\
\hline Multivessel coronary disease & $2.32(1.47-3.88)$ & 0.0002 & $2.69(1.69-4.52)$ & $<0.0001$ \\
\hline Mitral regurgitation grade $3 / 4$ & $1.99(1.10-3.33)$ & 0.02 & & \\
\hline Prior myocardial infarction & $1.37(0.97-1.91)$ & 0.07 & & \\
\hline Prior stroke & $1.73(1.15-2.52)$ & 0.009 & & \\
\hline Peripheral vascular disease & $2.12(1.30-3.29)$ & 0.0037 & & \\
\hline eGFR $<30$, not on dialysis & $4.21(2.54-6.88)$ & $<0.0001$ & $2.92(1.68-4.83)$ & 0.0003 \\
\hline Dialysis & $5.39(3.39-8.21)$ & $<0.0001$ & $3.24(1.92-5.31)$ & $<0.0001$ \\
\hline Atrial fibrillation & $2.45(1.54-3.73)$ & 0.003 & & \\
\hline Anemia (hemoglobin $<11 \mathrm{~g} / \mathrm{dl}$ ) & $4.61(3.23-6.49)$ & $<0.0001$ & $2.09(1.39-3.10)$ & 0.0005 \\
\hline Platelet $<100 * 10^{9} / \mathrm{L}$ & $2.71(0.96-5.95)$ & 0.06 & & \\
\hline Chronic obstructive pulmonary disease & $0.91(0.28-2.14)$ & 0.84 & & \\
\hline Liver cirrhosis & $0.91(0.23-2.41)$ & 0.87 & & \\
\hline Malignancy & $1.92(1.11-3.09)$ & 0.02 & & \\
\hline Target of proximal LAD & $1.20(0.86-1.69)$ & 0.29 & & \\
\hline Target of unprotected LMCA & $1.31(0.40-3.10)$ & 0.61 & & \\
\hline Cirostazole use & $0.95(0.56-1.51)$ & 0.83 & & \\
\hline Statins use & $0.43(0.30-0.60)$ & $<0.0001$ & $0.62(0.42-0.89)$ & 0.0092 \\
\hline Beta-blockers use & $0.90(0.62-1.27)$ & 0.55 & & \\
\hline ACE-I/ARB use & $0.66(0.48-0.92)$ & 0.01 & $0.62(0.44-0.87)$ & 0.0062 \\
\hline Nitrate use & $0.88(0.63-1.23)$ & 0.46 & & \\
\hline Calcium chanel blockers use & $0.87(0.62-1.22)$ & 0.43 & & \\
\hline
\end{tabular}




\begin{tabular}{lcc} 
Nicorandil use & $0.97(0.66-1.40)$ & 0.87 \\
Warfarin use & $1.33(0.76-2.16)$ & 0.3 \\
Proton pump inhibitors use & $1.86(1.30-2.3)$ & 0.001 \\
H2-blockers use & $0.92(0.61-1.35)$ & 0.67 \\
\hline
\end{tabular}

CTO indicated chronic total occlusion; BMI, body mass index; eGFR, estimated glomerular filtration rate; LAD, left anterior descending artery; LMCA, left main coronary artery; ACE-I, angiotensin converting enzyme inhibitors; ARB, angiotensin II receptor blockers. 


\section{Supplemental Figure 1}

(A)Number of patients underwent CTO-PCI in 26 centers

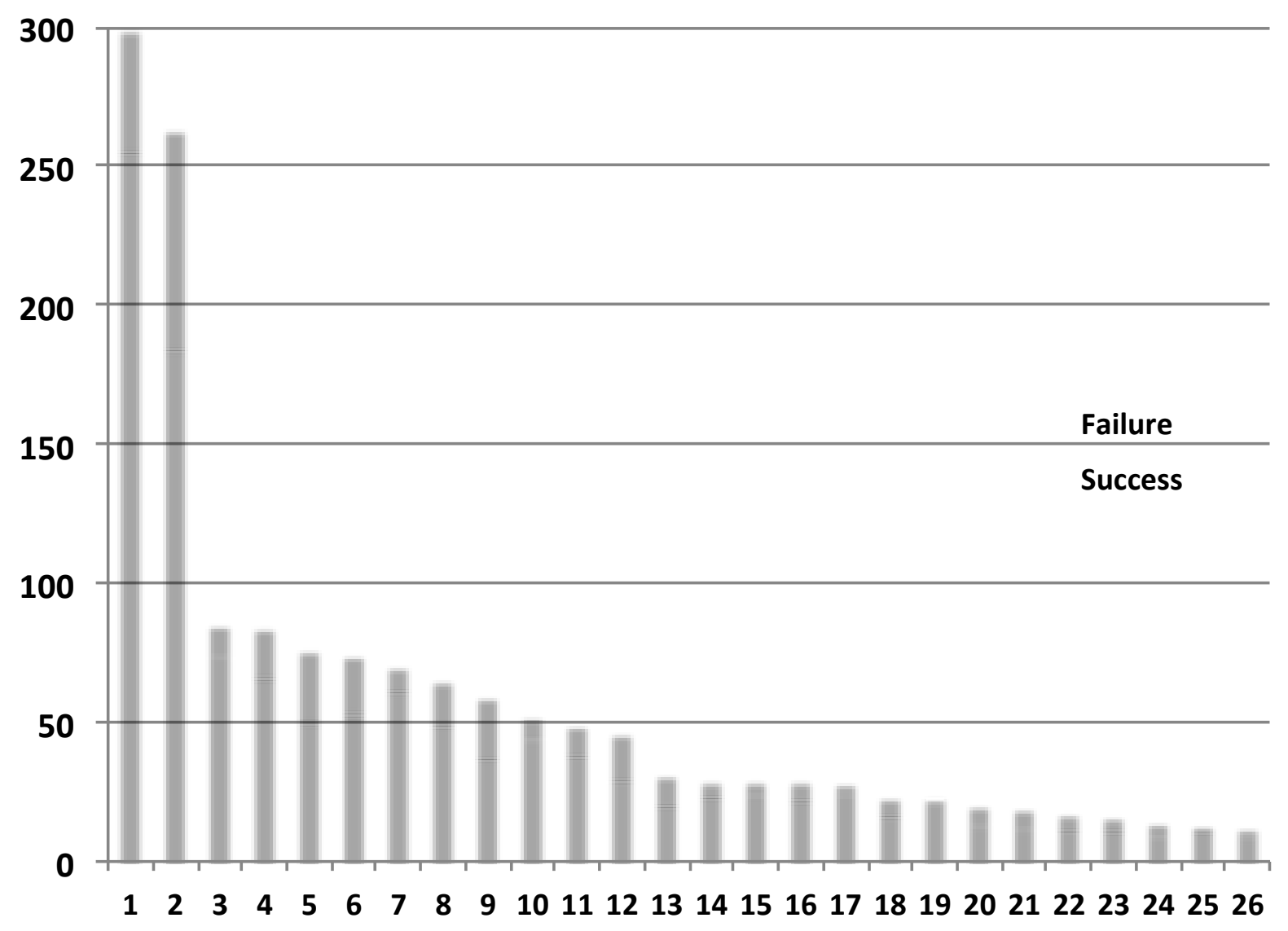


(B)Success rate of CTO-PCI in 26 centers

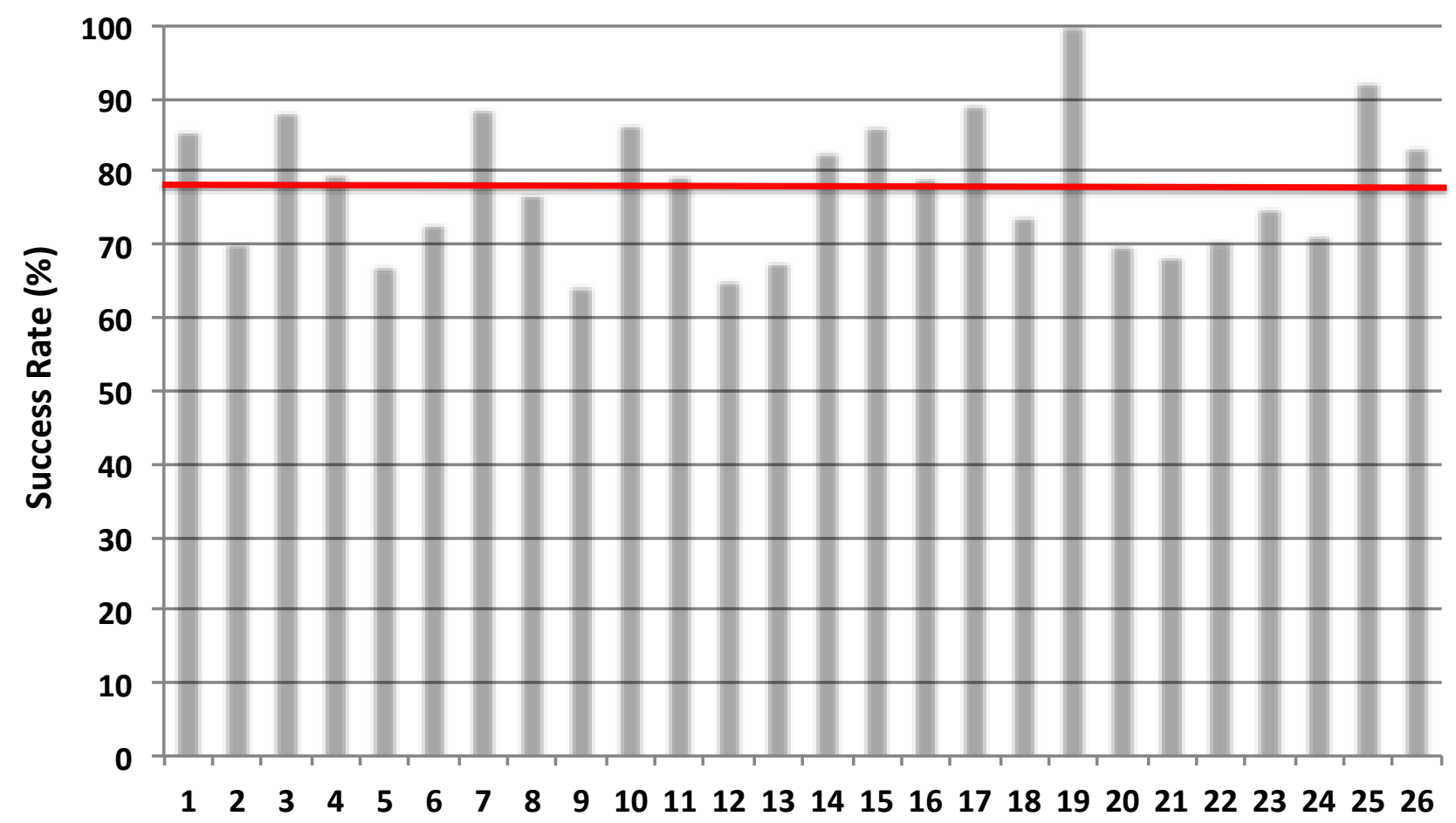


Supplemental Figure 2

(A) Persistent Discontinuation of Thienopyridine

\section{Persistent Discontinuation of Thienopyridine}

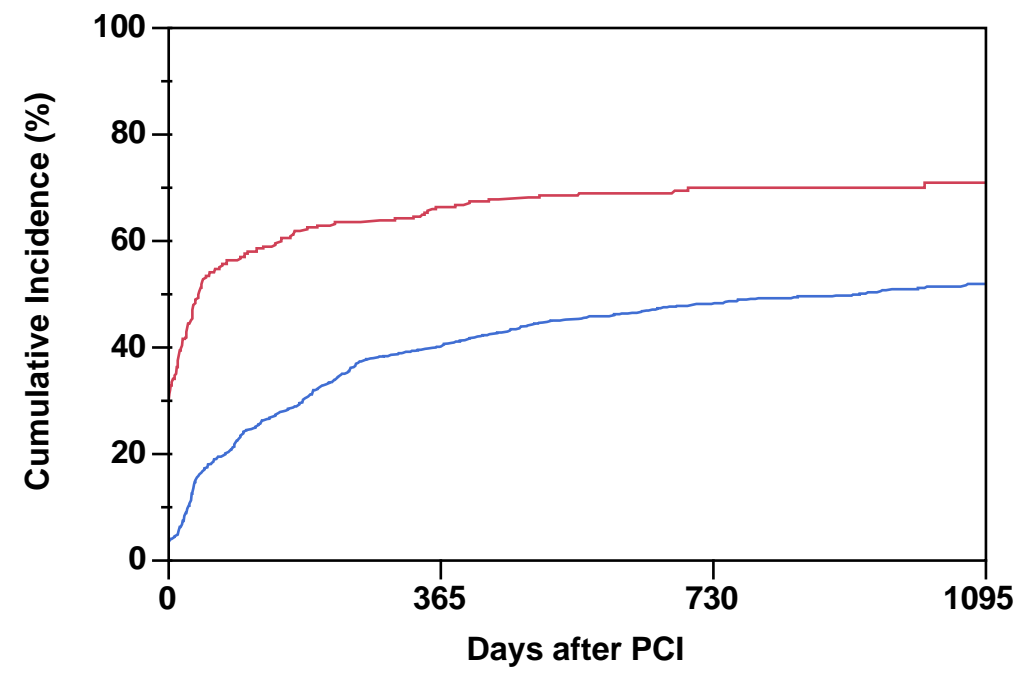

Failure

- Success

Log rank $p<0.0001$

\begin{tabular}{|c|c|c|c|c|c|}
\hline Interval & Odays & 30days & 1year & 2 years & 3years \\
\hline \multicolumn{6}{|l|}{ Success } \\
\hline Cumulative incidence & & $10 \%$ & $40 \%$ & $48 \%$ & $52 \%$ \\
\hline $\mathbf{N}$ of patients with event & & 122 & 456 & 538 & 558 \\
\hline $\mathrm{N}$ of patients at risk & 1192 & 1042 & 653 & 402 & 175 \\
\hline \multicolumn{6}{|l|}{ Failure } \\
\hline Cumulative incidence & & $45 \%$ & $66 \%$ & $70 \%$ & $71 \%$ \\
\hline$N$ of patients with event & & 146 & 212 & 221 & 222 \\
\hline $\mathrm{N}$ of patients at risk & 332 & 176 & 95 & 54 & 27 \\
\hline
\end{tabular}


(B) Persistent Discontinuation of Thienopyridine

\section{Persistent Discontinuation of Thienopyridine}

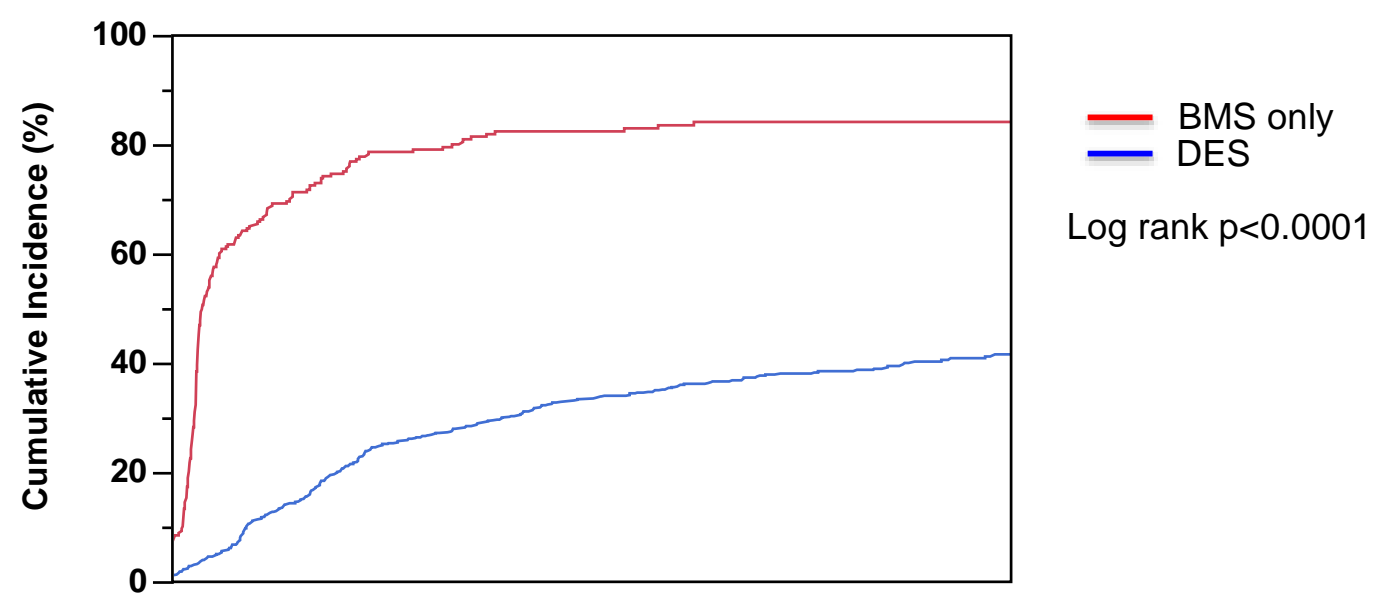

\begin{tabular}{lccccc} 
Interval & 0days & 30days & 1year & 2years & 3years \\
\hline DES & & & & & \\
\hline Cumulative incidence & & $2.8 \%$ & $27 \%$ & $37 \%$ & $41 \%$ \\
N of patients with event & & 26 & 234 & 305 & 325 \\
N of patients at risk & 900 & 852 & 601 & 374 & 161 \\
\hline BMS only & & & & & \\
\hline Cumulative incidence & & $29 \%$ & $79 \%$ & $84 \%$ & $84 \%$ \\
N of patients with event & & 73 & 194 & 203 & 203 \\
N of patients at risk & 256 & 177 & 45 & 25 & 14
\end{tabular}




\section{Supplemental Appendix A: List of participating centers and investigators for the CREDO-Kyoto PCI/CABG Registry Cohort-2}

\section{Cardiology}

Kyoto University Hospital: Takeshi Kimura

Kishiwada City Hospital: Mitsuo Matsuda, Hirokazu Mitsuoka

Tenri Hospital: Yoshihisa Nakagawa

Hyogo Prefectural Amagasaki Hospital: Hisayoshi Fujiwara, Yoshiki Takatsu, Ryoji Taniguchi

Kitano Hospital: Ryuji Nohara

Koto Memorial Hospital: Tomoyuki Murakami, Teruki Takeda

Kokura Memorial Hospital: Masakiyo Nobuyoshi, Masashi Iwabuchi

Maizuru Kyosai Hospital: Ryozo Tatami

Nara Hospital, Kinki University Faculty of Medicine: Manabu Shirotani

Kobe City Medical Center General Hospital: Toru Kita, Yutaka Furukawa, Natsuhiko Ehara

Nishi-Kobe Medical Center: Hiroshi Kato, Hiroshi Eizawa

Kansai Denryoku Hospital: Katsuhisa Ishii

Osaka Red Cross Hospital: Masaru Tanaka

University of Fukui Hospital: Jong-Dae Lee, Akira Nakano

Shizuoka City Shizuoka Hospital: Akinori Takizawa

Hamamatsu Rosai Hospital: Masaaki Takahashi

Shiga University of Medical Science Hospital: Minoru Horie, Hiroyuki Takashima

Japanese Red Cross Wakayama Medical Center: Takashi Tamura

Shimabara Hospital: Mamoru Takahashi

Kagoshima University Medica and Dental Hospital: Chuwa Tei, Shuichi Hamasaki

Shizuoka General Hospital: Hirofumi Kambara, Osamu Doi, Satoshi Kaburagi

Kurashiki Central Hospital: Kazuaki Mitsudo, Kazushige Kadota

Mitsubishi Kyoto Hospital: Shinji Miki, Tetsu Mizoguchi

Kumamoto University Hospital: Hisao Ogawa, Seigo Sugiyama

Shimada Municipal Hospital: Ryuichi Hattori, Takeshi Aoyama, Makoto Araki

Juntendo University Shizuoka Hospital: Satoru Suwa

\section{Cardiovascular Surgery}

Kyoto University Hospital: Ryuzo Sakata, Tadashi Ikeda, Akira Marui

Kishiwada City Hospital: Masahiko Onoe

Tenri Hospital: Kazuo Yamanaka

Hyogo Prefectural Amagasaki Hospital: Keiichi Fujiwara, Nobuhisa Ohno

Kokura Memorial Hospital: Michiya Hanyu

Maizuru Kyosai Hospital: Tsutomu Matsushita 
Nara Hospital, Kinki University Faculty of Medicine: Noboru Nishiwaki, Yuichi Yoshida Kobe City Medical Center General Hospital: Yukikatsu Okada, Michihiro Nasu

Osaka Red Cross Hospital: Shogo Nakayama

University of Fukui Hospital: Kuniyoshi Tanaka, Takaaki Koshiji, Koichi Morioka

Shizuoka City Shizuoka Hospital: Mitsuomi Shimamoto, Fumio Yamazaki

Hamamatsu Rosai Hospital: Junichiro Nishizawa

Japanese Red Cross Wakayama Medical Center: Masaki Aota

Shimabara Hospital: Takafumi Tabata

Kagoshima University Medica and Dental Hospital: Yutaka Imoto, Hiroyuki Yamamoto

Shizuoka General Hospital: Katsuhiko Matsuda, Masafumi Nara

Kurashiki Central Hospital: Tatsuhiko Komiya

Mitsubishi Kyoto Hospital: Hiroyuki Nakajima

Kumamoto University Hospital: Michio Kawasuji, Syuji Moriyama

Juntendo University Shizuoka Hospital: Keiichi Tanbara 


\section{Supplemental Appendix B: List of clinical research coordinators}

\section{Research Institute for Production Development}

Kumiko Kitagawa, Misato Yamauchi, Naoko Okamoto, Yumika Fujino, Saori Tezuka, Asuka Saeki, Miya Hanazawa, Yuki Sato, Chikako Hibi, Hitomi Sasae, Emi Takinami, Yuriko Uchida, Yuko Yamamoto, Satoko Nishida, Mai Yoshimoto, Sachiko Maeda, Izumi Miki, Saeko Minematsu.

\section{Supplemental Appendix C: List of clinical event committee members}

Mitsuru Abe (Kyoto Medical Center), Hiroki Shiomi (Kyoto University Hospital), Tomohisa Tada (Kyoto University Hospital), Junichi Tazaki (Kyoto University Hospital), Yoshihiro Kato (Kyoto University Hospital), Mamoru Hayano (Kyoto University Hospital), Akihiro Tokushige (Kyoto University Hospital), Masahiro Natsuaki (Kyoto University Hospital), Tetsu Nakajima (Kyoto University Hospital). 